\title{
Triple Intercostal Transthoracic Ports in Laparoscopic Hepatectomy for a Tumor in a Cranially Protruded Liver (with Video)
}

\author{
Koichiro Haruki, MD, PhD (D), Shinji Onda, MD, PhD, Tomohiko Taniai, MD, Mitsuru Yanagaki, MD, \\ Kenei Furukawa, MD, PhD, and Toru Ikegami, MD, PhD \\ Division of Hepatobiliary and Pancreatic Surgery, Department of Surgery, The Jikei University School of Medicine, \\ Tokyo, Japan
}

\begin{abstract}
Background. It is difficult to laparoscopically approach tumors of the anatomically anomalous right lobe of the liver, such as cranially protruded liver. The intercostal port has been useful for laparoscopic hepatectomy, especially for tumors located in the dome of the liver. PLoS One. 15:e0234919; Surg Endosc. 31:1280-1286; J Gastrointest Surg. 21:2135-2143; J Hepatobiliary Pancreat Sci. 21:E65-68; Surg Oncol. 38:101576; Thus, we introduce our technique using triple intercostal transthoracic ports for laparoscopic hepatectomy for hepatocellular carcinoma located in segment 8 . The right lobe of the liver was cranially protruded and located at the same level of the heart. Patient and Methods. The patient was placed in left lateral decubitus position. After the pneumoperitoneum and adhesiolysis, the hepatoduodenal ligament was controlled. Three additional intercostal ports with balloons were introduced transdiaphragmatically for liver parenchymal resection after confirmation of the lung edge by mandatory ventilation. A $12-\mathrm{mm}$ and a $5-\mathrm{mm}$ port were inserted into the sixth and seventh intercostal space for the operator's hands, while a 5-mm port was inserted into the fourth intercostal space for the assist's right hand. The liver parenchymal resection was performed using a cavitron ultrasonic surgical aspirator (CUSA) through the 12-mm intercostal port, followed by its completion without exposing the tumor. The $12-\mathrm{mm}$ port hole on the
\end{abstract}

(C) Society of Surgical Oncology 2022

First Received: 9 August 2021

Accepted: 16 January 2022;

Published Online: 6 February 2022

K. Haruki, MD, PhD

e-mail: haruki@jikei.ac.jp diaphragm was sutured and a 12-Fr chest tube was introduced in the right thoracic cavity.

Results. The operation time was $131 \mathrm{~min}$, and the blood loss was $20 \mathrm{~g}$. The patient was discharged on postoperative day 7 without any complication.

Conclusion. Triple intercostal ports could be a feasible procedure for a tumor with limited laparoscopic access from the abdominal port due to the anatomically anomalous liver.

Supplementary Information The online version contains supplementary material available at https://doi.org/10.1245/s10434022-11374-x.

FUNDING This work was supported by JSPS KAKENHI Grant Number JP21K08805.

DISCLOSURE The authors declare no conflict of interest.

\section{REFERENCES}

1. Hayashi H, Yamashita YI, Okabe H, et al. Varied application of intercostal trans-diaphragmatic ports for laparoscopic hepatectomy. PLoS One. 2020;15:e234919.

2. Ichida $\mathrm{H}$, Ishizawa $\mathrm{T}$, Tanaka $\mathrm{M}$, et al. Use of intercostal trocars for laparoscopic resection of subphrenic hepatic tumors. Surg Endosc. 2017;31:1280-6.

3. Inoue Y, Suzuki Y, Fujii K, et al. Laparoscopic liver resection using the lateral approach from intercostal ports in segments VI, VII, and VIII. J Gastrointest Surg. 2017;21:2135-43.

4. Lee W, Han HS, Yoon YS, Cho JY, Choi Y, Shin HK. Role of intercostal trocars on laparoscopic liver resection for tumors in segments 7 and 8. J Hepatobiliary Pancreat Sci. 2014;21:E65-68.

5. Ikegami T, Haruki K, Furukawa K, Onda S. Feasible laparoscopic repeat hepatectomy using double intercostal ports and laparoscopic vascular clamp (with video). Surg Oncol. 2021;38:101576.

Publisher's Note Springer Nature remains neutral with regard to jurisdictional claims in published maps and institutional affiliations. 